\title{
ARTIGO
}

\section{A CIRANDA CARTOGRÁFICA DE SABERES E CONHECIMENTOS}

The cartographic sieve of ability and knowledge

La ciranda cartográfica de habilidades y conocimiento

Alcides Leão Santos Júnior

Universidade do Estado do Rio Grande do Norte - Brasil

Álamo Gonçalves Pimentel

Universidade Federal do Sul da Bahia - Brasil

\begin{abstract}
Resumo
Descreve-se a Ciranda Cartográfica de Saberes e Conhecimentos como um dispositivo de pesquisa. Faz-se uso da Cartografia como um instrumento de preservação da representação do espaço não explorado, percorrido, visitado e experienciado pelos sujeitos. A proposta tem embasamento no pensamento do sociólogo Boaventura de Sousa Santos e procura evidenciar saberes e conhecimentos com o uso da representação como uma possibilidade de comunicação para traduzir graficamente saberes e conhecimentos e desnudar as falas dos sujeitos, de uma pesquisa de natureza qualitativa, articulando-as aos objetivos da mesma a fim de contribuir para uma leitura sem o direcionamento ou tratamento. Aponta-se que o dispositivo ao ser utilizado em uma pesquisa permite ao pesquisador uma maior aproximação com os sujeitos da sua pesquisa, bem como possibilita aos leitores (re)leituras do que foi pesquisado.
\end{abstract}

Palavras-chave: Cartografia. Epistemologia. Metodologia das ciências.

\begin{abstract}
The cartographic sieve of ability and knowledge is described as a research device. Cartography is used as an instrument for preserving the representation of space not explored, traveled, visited and experienced by the subjects. The proposal is based on the thought of the sociologist Boaventura de Sousa Santos and seeks to evidence knowledge with the use of representation as a communication possibility to graphically translate knowledge and to expose the subjects' speeches, a research of a qualitative nature, in order to contribute to a reading without direction or treatment. It is pointed out that the device when used in a research allows the researcher a greater approximation with the subjects of his research, as well as allows readers (re) readings of what was researched.
\end{abstract}

Keywords: Cartography. Epistemology. Methodology of the sciences.

Resumen 
La ciranda cartográfica de habilidades y conocimiento se describe como un dispositivo de investigación. Hágase el uso de la Cartografía como un instrumento de preservación de la representación del espacio no explorado, percorrido, visitado y experimentado por los sujetos. La propuesta tiene fundamento en el pensamiento del sociólogo Boaventura de Sousa Santos y procura evidenciar saberes y conocimientos con el uso de la representación como una posibilidad de comunicación para traducir gráficamente saberes y conocimientos y poner al descubierto las hablas de los sujetos, de una investigación cualitativa, articulando-las a los objetivos de la misma con el fin de contribuir a una lectura sin el direccionamiento o el tratamiento. Se señala que el dispositivo que se utilizará en una investigación permite al investigador una aproximación con los sujetos de su investigación, y permite a los lectores (re) lectura de lo que fue investigado.

Palabras clave: Cartografía. Epistemología. Metodología de la ciencia.

\section{Palavras iniciais}

Em uma sociedade que prima pela produção do conhecimento, percebe-se que ao longo dos tempos os humanos têm procurado utilizar os mais variados dispositivos ${ }^{1}$ para conservar e socializar suas experiências. Dessa forma, encontramos nas pesquisas acadêmicas um meio para que outros sujeitos possam conhecê-las ou até mesmo para produzir e colaborar com a construção da História da Humanidade. Diante desse repertório, indagamos: é possível através de uma metodologia de pesquisa evidenciar saberes e conhecimentos do vivido tornando os autores protagonistas da sua experiência?

Através dessa indagação, procuramos compor um trilhar metodológico para a escrita de uma tese no Programa de Pós-Graduação em Educação, da Universidade Federal da Bahia (UFBA), defendida em 28/02/13, intitulada A extensão universitária e os entre-laços de saberes. A orientação teórico-metodológica está ancorada no pensamento de Boaventura de Sousa Santos $(2005 ; 2004 ; 2000)$ quando o mesmo trata da Sociologia das Ausências e Emergências e, sobretudo, sobre a Cartografia Simbólica. O nosso trilhar recebeu a denominação de Ciranda Cartográfica de Sabres e Conhecimentos. Pretende-se descrever os artifícios e ritmos utilizados para a composição do caminhar.

Inicialmente, é preciso postular que evidenciar as maneiras pelas quais imaginamos os discursos do "outro" nos permite mapear as experiências vivenciadas pelos sujeitos de forma

\footnotetext{
1 Utilizamos o termo dispositivo na acepção de Giorgio Agamben (2014, p.39) "chamarei literalmente de dispositivo qualquer coisa que tenha de algum modo à capacidade de capturar, orientar, determinar, interceptar, modelar, controlar e assegurar os gestos, as condutas, as opiniões e os discursos dos seres viventes". Ao longo de todo o texto, o termo dispositivo remete ao conjunto de artefatos utilizados para a produção do conhecimento no âmbito da extensão universitária.
} 
que as representações possam ganhar (ou não) notoriedade. Assim, como dispositivo de pesquisa, indicamos a Ciranda Cartográfica de Saberes e Conhecimentos como um meio para evidenciar memórias e experiências do vivido.

\section{A Ciranda Cartográfica de Saberes e Conhecimentos como dispositivo de pesquisa}

Ao apontarmos a Ciranda Cartográfica de Saberes e Conhecimentos como um dispositivo de pesquisa, a apreensão inicial parte da compreensão que a Cartografia é um instrumento ou dispositivo de conservação e preservação da representação do espaço não explorado, percorrido, visitado e experienciado pelos sujeitos. Sendo assim, ao descrevermos como a Ciranda Cartográfica de Saberes e Conhecimentos surge como um dispositivo de pesquisa, lembramos que Joly (1990, p. 31) nos diz que, ao longo do tempo, os homens: "aprenderam a gravar os seus detalhes em placas de argilas, madeira ou metal, ou desenhá-los nos tecidos, nos papiros e nos pergaminhos. Assim, aprenderam no Egito, na Assíria, na Fenícia e na China os primeiros esboços cartográficos".

A utilização da cartografia é muito difundida na história da humanidade e serviu tanto para os comerciantes quanto para os militares defenderem os limites de seus Estados. Os primeiros mapas foram traçados a partir de relatos orais de viajantes; hoje, já vimos que os satélites espalhados pelo cosmos mostram como a realidade e os espaços são mutáveis. Isso também favoreceu o uso de cartografia para registros de saberes e bens imateriais em determinados espaços sociais e culturais como forma de preservação do lugar no cotidiano, como diria Milton Santos (SANTOS, 2000a).

Não queremos fazer ou traçar, aqui, um histórico da cartografia, mesmo porque este não é nosso objeto de estudo e, também, porque existe uma gama de referências que dão conta dessa questão. O próprio Boaventura de Sousa Santos nos oferece uma consistente articulação entre referências teóricas da geografia com a teoria social das representações quando nos propõe a tal Cartografia das Representações Sociais do Direito (SANTOS, 2000). Nossa proposta centra-se apenas em evidenciar saberes e conhecimentos com o uso desta forma de representação como uma possibilidade de comunicação para traduzir graficamente saberes e conhecimentos.

A proposta, que ora se delineia para o aporte metodológico, ganha força no dizer de Cunha (2006, p.11) quando advoga que: 


\begin{abstract}
Apesar de muitas vezes se recuperarem vozes silenciadas, as formas de pensar e processar estas fontes de conhecimentos não romperam, na maior parte dos casos e no fundamental, com os paradigmas dominantes que são perspectivas constitutivas do conhecimento dominante. Nesta medida, a geopolítica do conhecimento não é mais uma abordagem epistemológica, mas é o lugar político da ciência. $O$ postulado da diferença, da heterogeneidade, da mestiçagem, da hibridização, da contingência, é profundamente político e tem que ser levado a sério, sob pena de se estabelecerem apenas trocas desiguais.
\end{abstract}

Tentando não estabelecer trocas desiguais entre os sujeitos da pesquisa e o pesquisador, enfatizamos que a opção em trabalhar com a Cartografia Simbólica ou com a Sociologia Cartográfica proposta por Santos $(2005,2004,2000)$ remonta à questão de que tal dispositivo ou procedimento de sistematização de informações nos conduz à compreensão de que a ciência é complexa e combina características tanto das Ciências Naturais quanto das Ciências Sociais (SANTOS, 2005, p. 197). Assim, uma Cartografia pode satisfazer a intenção de evidenciar conhecimentos antagônicos em modos comunicativos acessíveis favorecendo o processo de construção de conhecimento nas diversas áreas do conhecimento.

Esclarecemos que a Associação Cartográfica Internacional, conforme Joly (1990, p. 8 - 9), em reunião na UNESCO, abril de 1966, Paris, definiu a cartografia como “[...] o conjunto dos estudos e das operações científicas, artísticas e técnicas que intervém a partir dos resultados de observações diretas ou da exploração de uma documentação, em vista da elaboração e do estabelecimento de mapas, planos e outros modos de expressão, assim como de sua utilização".

A partir de um estudo sobre a utilização da Cartografia, Brito e Hetkowski (2009, s.p.) informam que este conceito considera:

[...] que os usuários dos produtos cartográficos também estão produzindo cartografia, pois existe uma clara interação entre os mapas e seus usuários. Interação está relacionada com a representação dos elementos ou fenômenos, bem como com a sua interpretação. Assim, podemos tomar a Cartografia como linguagem, uma forma de apresentar e representar a superfície terrestre e seus elementos através de um alfabeto próprio, o qual se utiliza signos (símbolos), bem como de figuras geométricas (pontos, linhas e polígonos) na composição de suas mensagens.

Diante dessa observação, podemos inferir que a Cartografia é uma estratégia de suspensão do tempo, que cria ambiente para o espaço que engloba, segundo Joly (1990, p. 9), parte de "[...] todas as atividades que vão do levantamento do campo ou da pesquisa bibliográfica até a impressão definitiva e a publicação do mapa elaborado”. Dessa forma, esta suspensão se dá porque os acontecimentos históricos fazem parte da ontologia do ser e podem 
ser combinados entre o ontem, o hoje e o amanhã em um movimento que direciona a essência do humano que vive, constrói e imagina sua realidade, buscando concretizar seus ideais.

Merece destaque aqui o uso que o leitor faz dos mapas, pois, conforme Brito e Hetkowshi (2009, s.p.), a junção entre os conhecimentos do:

[...] emissor e do receptor propicia o crescimento científico, em que saber individual é transposto. Desta forma, a informação que sai é maior do que a que entra: a informação é objetiva, pois foi produzida sistematicamente através de um método científico, mas a interpretação pode sofrer influências por parte de cada especificidade dos leitores.

É com esse dimensionamento que projetamos a Cartografia enquanto dispositivo de pesquisa que procura sistematizar seus dados em um mapa elaborado cujo conteúdo informe a dinâmica do espaço/tempo experienciado pelos sujeitos da pesquisa. Assim, se a Cartografia relaciona o tempo geográfico ao histórico, podemos entender que este dispositivo possa ser "[...] antes de tudo uma mensagem de localização e de avaliação de distancias e de orientações”. (JOLY, 2004, p. 9); no caso em pauta, de orientação para a prática universitária.

Como temos enquanto aporte teórico embasamento no Pensamento Complexo, não é demais lembrar que Morin (2007, p. 192) nos diz que a complexidade não possui uma metodologia, mas esta pode ter um método e como nossa tese é que na extensão universitária de cunho acadêmico as fronteiras disciplinares dissipam-se, a nossa ideia é fazer com que estes saberes e conhecimentos possam dialogar. Sabemos que a participação em atividades de pesquisa e extensão é escolha dos estudantes. Contudo, cabe às Instituições de Ensino o estimulo à participação nas ações de extensão universitária para que os mesmos possam obter uma formação condizente com o verdadeiro sentido/significado de uma Universidade e que consigam, assim, ao longo do período formativo, vivenciarem experiências que proporcionam a reflexão/ação/reflexão sobre os conhecimentos que são difundidos no espaço acadêmico e que necessitam serem materializados. Para que esta práxis aconteça é necessário um currículo flexível.

Se hoje vemos uma adequação curricular que atenda às exigências de mercado e uma formação profissional com tendências economicistas e mercantilistas, portanto refém da racionalidade econômica, projetar uma ação que prima pelo diálogo com e na comunidade trata-se do rompimento com as estruturas preconcebidas e com as disputas ideológicas para poder alcançar uma formação que contemple uma postura mais humilde e verdadeiramente humana. Essa atitude só ocorrerá quando o diálogo superar as barreiras hierarquizantes presentes no seio da comunidade acadêmica. 
Pode-se entender a flexibilização curricular como uma possibilidade de satisfação das necessidades educativas que não podem ser entendidas como uma atividade complementar presente na estrutura curricular. É uma forma de tornar o currículo mais acessível sem empobrecê-lo.

Flexibilizar o currículo demanda, também, que os processos de conhecimentos respeitem e valorizem as diversidades de saberes, conhecimentos e experiências que orientam as atividades realizadas nas e pelas universidades. Sobre a extensão, Andrade (2004. p. 34) comenta que ela é:

[...] o mecanismo mais eficiente de aproximar a instituição universitária da sociedade ao seu redor, funcionando como o meio mais eficiente de ampliar o acesso à Universidade, de milhares de cidadãos que a ela não têm acesso pela via do ensino formal [...] a extensão é também a possibilidade da síntese teórica e prática da experimentação social, elementos fundamentais para uma formação acadêmica referenciada na realidade social, nas suas necessidades, na sua singularidade.

Assim entendido, flexibilizar o currículo é permitir que os estudantes concebam a sociedade como uma instituição dinâmica que produz o tempo todo conhecimentos novos e que os coloca à disposição das Universidades. Não significa aqui olharmos para a sociedade enquanto instrumento de pesquisa, mas como um espaço propício para o diálogo e onde a troca de saberes se faz naturalmente.

A Atividade Curricular em Comunidade (ACC) é uma experiência de flexibilização curricular que faz emergir uma nova forma de "fazer" Universidade. É uma nova lógica de fazer com que a produção da não existência e de uma monocultura racional sejam substituída pela cultura do re-ligar. É uma possibilidade de fornecer visibilidade ao que nos circula. Poderia ser o reconhecimento através da sociologia das ausências, que para Santos (2004. p. 14) é “[...] uma investigação que visa demonstrar que o que não existe é, na verdade, ativamente produzido como não-existente, isto é, como uma alternativa não-credível ao que existe".

O autor completa, ainda, dizendo que "o objetivo da sociologia das ausências é transformar objetos impossíveis em possíveis, objetos ausentes em presentes”. (SANTOS, 2004. p. 14).

A visibilidade que a ACC proporciona aos sujeitos envolvidos nas ações faz com que os saberes historicamente construídos sejam transformados em conhecimentos validos e visíveis. Santos (2004. p. 157) distingue cinco lógicas ou modos da produção da nãoexistência Na primeira, que denomina a monocultura do saber e do rigor do saber enfatiza 
que esta lógica é a mais poderosa pois "transforma a ciência moderna e a alta cultura nos únicos critérios de verdade". Completa, afirmando que "a não-existência assume aqui a forma de ignorância ou de incultura. Na segunda a monocultura do tempo linear aborda a ideia de que a "história tem sentido e direção único e conhecido"; o tempo é linear e na sua frente seguem os países centrais; na terceira, denominada a monocultura da naturalização das diferenças explicita que as populações são classificadas segundo categorias hierarquizantes (racial, sexual, dentre outras) que deixa evidente que a relação de dominação é a consequência e não a causa dessa hierarquização; na quarta lógica, a monocultura do universal e do global que é tida como a lógica da produção da não-existência que é produzida sob a forma do particular e do local e por fim apresenta a monocultura dos critérios de produtividade e de eficácia capitalista traz a ideia de que o trabalho é uma força produtiva que torna as populações descartáveis. (SANTOS, 2004).

Estas monoculturas, produzidas pela epistemologia e pela racionalidade hegemônica, são resultantes de uma lógica de produção social que intensifica e converge no desperdício das experiências sociais. Para Santos (2004. p. 18), a sociologia das ausências "funciona mediante a substituição das monoculturas por ecologias". (Dos saberes, das temporalidades, dos reconhecimentos, das trans-escalas e das produtividades).

Para fins de exposição, nos atemos à ecologia dos saberes porque nela está explícita a compreensão de incompletude e a possibilidade do diálogo entre os conhecimentos que são fatores essenciais para que a flexibilização curricular aconteça. Neste domínio, na ecologia de saberes os saberes não científicos são possibilidades outras ao saber científico. Destaca-se que não utilizaremos aqui a ideia de Santos de alternativa porque na nossa compreensão estes saberes estão postos e não necessitam serem validados nem pela academia tampouco por outras instituições.

É, pois, um não programático, mas paradigmático no que diz respeito à democratização, organização e construção dos conhecimentos tendo em vista " [...] a lógica da monocultura do saber e do rigor cientifico tem de ser confrontado pela identificação de outros saberes e de outros critérios de rigor que operam credivelmente em práticas sociais". (SANTOS, 2004. p. 18).

Ao procurarmos analisar e estudar os fenômenos educacionais, à luz do pensamento de Santos, nos damos conta de que estes são repletos de sentidos de curiosidades e de amorosidade para, pelos e com nossos estudantes. 
Assim, nos deparamos com uma concepção de sociologia das emergências que é uma "[...] investigação das alternativas que cabem no horizonte das possibilidades concretas [...]". (SANTOS, 2004. p. 25).

Temos o espaço acadêmico e escolar como possibilidades outras favorável à convivência humana que tem a educação como uma manifestação objetiva e subjetiva de materialização e propagação do conviver e do amor. Acompanhando as demandas de uma educação que visa minimizar a dicotomia teoria e prática, não podemos pautá-la no princípio simplificador e disciplinarista, precisamos proporcionar aos estudantes vivências em comunidades para que a aquisição de novos conhecimentos contribuam na construção de uma visão crítica.

Em suma, pensar a flexibilização curricular na extensão universitária requer projetar um novo "fazer" universitário, haja vista que essa ação rompe com a estrutura linear do "currículo tradicional" e nos remete a possibilidades outras de um currículo complexus e multirreferencial que deságua numa proposta de uma epistemologia curriculista que busca superar, desconstruir e transgredir qualquer lógica linear e disciplinarista e que tenha uma identidade física. Assim, trata-se de uma ação ética e política que demanda olhar para as relações de alteridade presentes nos discursos e fazeres dos sujeitos sociais.

Neste sentido, a ACC é uma ação de extensão universitária que não subestima os saberes e conhecimentos produzidos no/pelo senso comum, pois o que se aprende na academia não pode, nem deve, ser entendido como superior a ponto de sobrepor as informações que se tem nas comunidades. Esta atitude, no nosso entendimento, faz as diversas experiências vivenciadas pelos sujeitos sociais produzirem saberes e mostrarem que o conhecimento científico somente tem sentido quando articulado com outros saberes/conhecimentos. Para a escrita da tese que visava difundir a produção de conhecimento pela via do entrelaçamento Universidade e Sociedade, propomos a Ciranda Cartográfica de Saberes e Conhecimentos como percurso metodológico que surgiu como um dispositivo de pesquisa que procura desnudar as falas dos sujeitos, de uma pesquisa de natureza qualitativa, articulando-as aos objetivos da mesma a fim de contribuir para uma leitura sem o direcionamento ou tratamento às falas, às narrativas, às histórias de vida e às memórias dos sujeitos da pesquisa. Ela é uma forma de diálogo entre o pesquisador com os sujeitos da pesquisa e que pode ser (re)lida com outros olhos pelos leitores.

O conhecimento incorporado para projetar a Ciranda Cartográfica de Saberes e Conhecimentos origina-se, também, em uma tentativa de exercício e procura por uma justiça 
cognitiva que muitas vezes não é dada quando fazemos tratamentos das falas dos sujeitos na pesquisa acadêmica.

Assim, o primeiro contato e interesse pela metodologia tem sua gênese quando participávamos do Grupo de Estudos Boaventura, um grupo da linha de pesquisa em Educação, Estado e Sociedade, do Programa de Pós-Graduação em Ciências Sociais (PPGCS) da Universidade Federal do Rio Grande do Norte (UFRN), grupo que frequentávamos no momento quando estávamos matriculados como estudante no referido PPGCS-UFRN e, neste, alguns pesquisadores estavam desenvolvendo seus trabalhos fazendo uso da Cartografia Simbólica com base no pensamento de Boaventura de Sousa Santos.

Em termos de conteúdo, a Ciranda Cartográfica de Saberes e Conhecimentos apresenta uma composição simbólica que procura trazer informações ao leitor sobre o vivido/vivenciado. O mapa que procuramos esboçar constitui-se em um conjunto de símbolos, de letras e de cores, de modo que sua mensagem possa ser entendida com facilidade (DUARTE, 1991)

Em relação ao conteúdo informacional de um mapa, podemos ainda destacar que ele pode ser utilizado como possibilitador de leitura e de representação. Desse modo, mesmo com o advento do avanço das tecnologias, Rodrigues e Souza (2008, p. 66) nos diz que a informação é um:

[...] documento cartográfico tem escala e uma organização espacial baseada numa projeção ortogonal da superfície terrestre sobre o plano. A representação da mensagem por meio de signos encontra-se diretamente condicionada à característica do fenômeno e aos dados disponíveis. Neste caso, são os signos projetados, modificados e agrupados individualmente, que refletem o propósito de um determinado mapa, por meio de uma dada composição simbólica.

A proposta que se delineia de apresentarmos uma Ciranda Cartográfica de Saberes e Conhecimentos ganha força a partir do pensamento de Borba (1998, p. 17) quando diz que precisamos sair do conformismo das metodologias prontas. Pois, no "[...] fazer ciência, o criar, o construir ciência que definirá a "composição" (a bricolagem) metodológica. É na construção do campo de pesquisa que se define a elaboração (in loco) das metodologias (a composição inteligente das mesmas), e não o inverso".

A nossa tentativa de transgressão configura-se em (re) criar e mapear os diálogos entre sujeitos da nossa pesquisa. Isso porque "[...] o conhecimento oriundo da análise multirreferencial é "tecido" (bricolado): ele se estabelece a partir da convergência, ou melhor, da convivência, do diálogo trans, pluri, interdisciplinarmente" (MARTINS, 1998, p. 23). 
Assim, nosso mapa de entrelaçamentos de saberes e conhecimentos parte das vivências e possui a seguinte configuração:

\section{FIGURA Nº1 - CIRANDA CARTOGRÁFICA DE SABERES E CONHECIMENTOS}

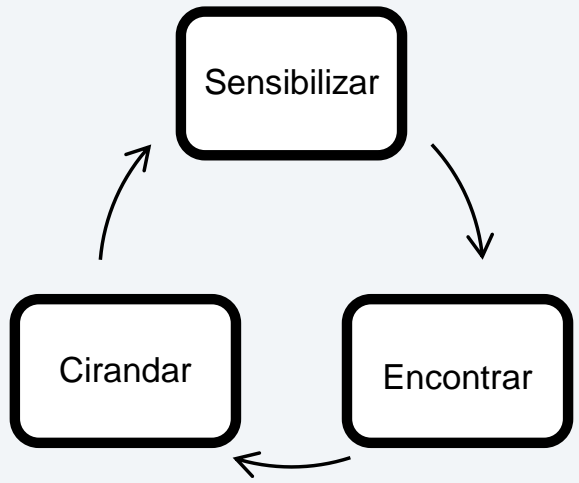

Fonte: SANTOS JÚNIOR (2013, p. 154)

As expressões que aparecem na Figura $\mathrm{N}^{\mathrm{o}} 01$ (sensibilizar, encontrar e cirandar) dizem respeito aos momentos de desenvolvimento da pesquisa a partir da forma com a qual estabelecemos os encontros com os sujeitos da pesquisa. Dessa forma, o cirandar corresponde a uma brincadeira de crianças bastante comum no Nordeste do Brasil que evidencia a não hierarquização de saberes. Essas brincadeiras mostram que não há um saber hierárquico, tampouco uma centralidade, pois em uma ciranda todos estão no mesmo patamar; todos se olham, se veem, se enxergam e se sentem, se ouvem e se movimentam em um mesmo ritmo acompanhando as canções da ciranda. No interior da ciranda, saberes e fazeres circulam, alteram-se e transformam-se conforme as posições e os diferentes ritmos de participação daqueles que congregam a experiência vivida na produção do conhecimento.

O sensibilizar assenta na conversação e na forma como o pesquisador vai ao encontro do sujeito da pesquisa procurando sempre evidenciar uma convivência democrática entre diferentes saberes e conhecimentos baseada no respeito à diferença, que se caracteriza no reconhecimento do "outro". Dessa forma, lembramo-nos das palavras de Ardoino (apud BORBA, 2012, p. 82) quando nos diz que "o conhecimento científico, ao invés de ser uma Torre de Babel, deve ser poliglota".

Como se trata de uma proposta metodológica que visa aproximar diferenças étnicoculturais e sociais promovendo um entrelaçamento de saberes, fazendo uso do encontro e produzindo traduções interculturais dos saberes produzidos, vislumbramos este momento como sendo um deslocamento intercultural para mapear as falas dos sujeitos de uma pesquisa. 
Fleury (2003, p. 17) comenta que o adjetivo intercultural “[...] tem sido utilizado para indicar realidades e perspectivas incongruentes entre si: há quem o reduz ao significado de relação entre grupos "folclóricos"; há quem amplia o conceito de interculturalidade de modo a compreender o "diferente" que caracteriza a singularidade e a irrepetibilidade de cada sujeito humano; há ainda quem considera interculturalidade como sinônimo de "mestiçagem". Ainda sobre a interculturalidade, Pimentel $(2012$, p. 24) completa afirmando que:

[...] como dinâmica do encontro e da complementariedade na diversidade, é uma das interpretações apreensíveis das contribuições de Boaventura de Sousa Santos para a compreensão da escola e dos espaços não escolares de produção de conhecimento como paradigmas de organizações sociais planetárias na contemporaneidade, também produtores de ecologias de saberes que exigem novas traduções interculturais.

A interculturalidade pode ser entendida como um momento de conversação que coloca ênfase no respeito, no direito a ser diferente e na denúncia as visões que procuram justificar a xenofobia, o racismo, a marginalização e a exclusão social. Assim, os elementos fundantes de uma Ciranda Cartografia de Saberes e Conhecimentos estão inter-relacionados.

Em suma, imaginamos que esses passos na construção de um dispositivo metodológico pode favorecer o pesquisador a evidenciar memórias e conhecimentos de diferentes sujeitos, procurando, entrelaçar novas possibilidades de conhecer e de socializar conhecimentos.

\section{Os entrelaços de saberes e conhecimentos em uma Ciranda Cartográfica de Saberes e Conhecimentos}

A Ciranda Cartográfica de Saberes e Conhecimentos, por nós proposta como um dispositivo de pesquisa, representa uma realidade e experiências que podem ser mapeadas/cartografadas para serem traduzidas e lidas como modo credível. Sob esse aspecto, Santos (2005, p. 201) nos lembra que os mapas distorcem uma realidade através de três mecanismos: a escala, a projeção e a simbolização.

Sobre isso, esclarecemos que, como mecanismo, a escala é, segundo Joly (1990, p. 20), a “[...] relação constante entre as distâncias lineares medidas sobre o mapa e as distâncias lineares correspondentes [...]", é o elemento que promove a representação/distorção da realidade. Quanto maior a escala maior será a possibilidade de elementos a serem desvendados. 
A escala é um elemento de opacidade das múltiplas referências que estão presentes em uma realidade. Para Joly (1990, p. 8), ela determina um “[...] certo nível de análise em função do espaço a cobrir e dos detalhes a atingir [...] no estágio da redação, a escala é a condição da precisão, da legibilidade, da boa apresentação e da eficiência do mapa”. Logo, a escala funciona como o elemento que desvela ou oculta situações. Contudo é preciso atentar que "um dado fenômeno só pode ser representado numa dada escala. Mudar de escala implica mudar o fenômeno" (SANTOS, 2005, p. 202).

Na Ciranda Cartografia de Saberes e Conhecimentos, a escala pode ser compreendida como a opção que fizemos em trazer à tona a fala de alguns sujeitos da pesquisa sem a preocupação de uma análise de discurso. Apenas as aproximamos a contextos e a situações diferentes.

A projeção é um elemento importante para a confecção de um mapa. Diferente de outras formas de retratar um espaço, a projeção, na cartografia, planifica dados. Para Santos (2005, p. 203), “cada tipo de projeção cria um campo de representação no qual as formas e os graus de distorção têm lugar segundo regras conhecidas e precisas”. Em verdade, a projeção pode distorcer certa realidade tendo em vista a opção ideológica do cartógrafo e a finalidade/objetivo do mapa. Destacamos aqui que a projeção centraliza certo ponto e torna periféricos outros; essa atitude faz com que o conhecimento seja evidenciado de forma centralizadora. Sendo assim, a projeção na Ciranda Cartográfica de Saberes e Conhecimentos refere-se à escolha em recortar falas e permitir que outras possam ser (re)lidas, mas nunca silenciadas.

Diante de uma complexidade de situações e da variedade de elementos presentes na realidade vivida pelos sujeitos, os símbolos gráficos sempre estiveram presentes. Nesse sentido, Joly (1990, p. 8) comenta que o “[...] número e o acúmulo dos símbolos empregados dependem, com efeito, do espaço disponível; quanto maior a redução da imagem terrestre (ou seja, quanto menor for a escala), mais severa é a seleção e mais abstrata a simbologia".

Na linguagem cartográfica, é fundamental uma convenção para que a leitura cartográfica seja mais rápida e eficaz. Todavia, esta não é uma regra geral, haja vista a utilização de legendas.

Santos $(2005$, p. 207) completa dizendo que a simbolização "[...] é a face visível da representação da realidade; é o procedimento técnico mais complexo, pois que a sua execução é condicionada tanto pelo tipo de escala, como pelo tipo de projeção adaptados”. 
Esses mecanismos (a escala, a projeção e a simbolização) são autônomos, “[...] envolvem procedimentos distintos e exigem decisões específicas” (SANTOS, 2005, p. 201). Assim, um mapa deve ser uma forma sintética/resumida de representação. Para tanto, precisa envolver o maior número de dados para uma leitura rápida e precisa.

Para a coleta dos dados, a utilização do questionário aberto, da entrevista semiestruturada e da análise documental podem favorecer a confecção de uma Ciranda Cartografia de Saberes e Conhecimentos. A utilização do questionário aberto se justifica pela possibilidade de uma maior aproximação com o pensamento dos sujeitos, propiciando-lhes a livre expressão, a análise e a crítica. Sugere-se elaborar questões indexalizadas ao contexto do estudo, apontando para as questões nucleares do problema de pesquisa; sugerindo aos respondentes que argumentem, justifiquem, contextualizem e explicitem as suas respostas. A entrevista semiestruturada possibilita o aprofundamento de questões emergentes durante a entrevista, oportunizando a construção de sentidos pelos entrevistados. Ela permite a compreensão de uma realidade que não se manifesta apenas a partir da linguagem oral porque, segundo Macedo (2000, p. 164), “[...] a linguagem aqui é um forte fator de mediação para a apreensão da realidade e não se restringe à noção de verbalização. Há toda uma gama de gestos e expressões densas de conteúdos indexais importantes para a compreensão das práticas cotidianas". (MACEDO, 2000)

As entrevistas individuais e/ou coletivas quando aplicadas de modo aprofundado fomenta a minimização de dúvidas e esclarece ambiguidades, além de favorecer o entrelaçamento de experiências de vida. Por último, pode-se aplicar questionários abertos a fim de solucionar dificuldades decorrentes de participantes que se recusassem a conceder entrevista. Por tratar-se de uma pesquisa qualitativa após as entrevistas, que devem ser gravadas, procede-se com a transcrição das falas dos sujeitos. Visando tentar não promover um desperdício de experiências, ao realizar este procedimento, indica-se fazer uso da ecologia dos saberes e da tradução, pressupostos na Cartografia Simbólica (SANTOS, 2005, 2004, 2000), para criar a Ciranda Cartográfica de Saberes e Conhecimentos.

Cremos que este dispositivo de pesquisa tenta extrapolar os modos convencionais de confirmar hipóteses, pois se faz o uso da suspensão temporal e geográfica, da escala, da projeção e das distorções encontradas no processo da pesquisa e permite ao pesquisador entrelaçar memórias, saberes e conhecimentos de forma plástica. Neste sentido, postulamos que através de uma Ciranda Cartográfica de Saberes e Conhecimentos as memórias dos 
sujeitos estarão sendo valorizadas e através delas estamos produzindo um conhecimento por meio de saberes, de memórias e de experiências vividas.

Obviamente, estas são sugestões para a elaboração e delineamento de uma proposta. Outras formas de cartografar saberes e conhecimentos podem e devem surgir dependendo do objetivo e leitura de mundo do sujeito. Pois, como comenta Joly (1990, p. 17), os objetos cartografados são “[...] transcritos através de grafismos ou símbolos, que resultam de uma convenção proposta ao leitor pelo redator, e que é lembrada num quadro de sinais ou legenda do mapa".

Dentro de nossos limites, construímos a Ciranda Cartográfica de Saberes e Conhecimentos conforme a proposta de Santos (2002, p. 222) ressaltando que o sociólogo português sugere que vale "[...] a pena testar as virtualidades teóricas e analíticas da Cartografia Simbólica no estudo de outras representações sociais além do direito”. E foi isso que nos moveu à criação da Ciranda Cartográfica de Saberes e Conhecimentos, aqui apresentada, como modo singular de simbolização de entrelaçar vozes e experiências, de representação social de uma prática social e coletiva acreditando que a Cartografia viabiliza concretizar a realidade dos sujeitos que se utilizam dos mapas para dar sentido à construção de conhecimento, para concretizar e fazer sentido sua existência e práticas sociais e culturais, localizando-as no espaço e no tempo histórico.

Em suma, enfatizamos que para o entrelaçamento de saberes e conhecimentos pela via da Ciranda Cartográfica de Saberes e Conhecimentos é preciso ter claro que, sendo mapas, as experiências cartografadas são distorções reguladas de uma realidade, distorções organizadas de territórios que criam ilusões credíveis de correspondência, portanto o conhecimento produzido neste entrelaçamento é inacabado e está inserido na dinâmica da vida em sociedade que é mutável e permeável ao longo do tempo, mas que permite leituras no presente, do vivido no passado sempre capacitante.

\section{Considerações}

Tal como os mapas que direcionam caminhos ou até mostram o itinerário percorrido, a proposta de apresentar uma Ciranda Cartográfica de Saberes e Conhecimentos enquanto um dispositivo de pesquisa acadêmica traz as experiências e vivências dos sujeitos e nelas são evidenciadas lembranças do vivido. 
Como as experiências vividas descritas em uma Ciranda Cartográfica de Saberes e Conhecimentos são memórias, lembramos que algumas distorções do vivido pelas brechas do tempo-histórico e social podem ser evidenciadas ou até mesmo não sendo apontadas pelo pesquisador. Mas, como um mapa que precisa de escalas e projeções, um olhar atento de outros sujeitos poderá a partir do que foi evidenciado apontar novos caminhos. Com essa compreensão, podemos pensar que para operar esta metamorfose vale a pena frisar que se um mapa distorce uma realidade para instruir uma possível orientação às experiências e vivências, estas podem ter distorções do nosso ser/estar em um tempo-espaço que nos concretiza como sujeitos.

Diante dessa perspectiva, distorções não caóticas, orientadas para um fim, o de fazer compreender que a experiência do outro não é sua, mas que contém saberes, práticas sociais e culturais que carecem serem visualizadas e respeitadas, precisamos fazer ciência de procedimentos de pesquisas que procurem valorizar o "outro". Pois seus saberes podem ser necessários para nos situarmos em um tempo espaço-histórico e social que, embora não tenha sido experienciado por nós, poderá contribuir para que o mesmo se torne objeto cognoscente de nossas experiências de nossa construção de conhecimentos. Assim, tratamos a Ciranda Cartografia de Saberes e Conhecimentos como um dispositivo de pesquisa dialógico e político-social que, na sua dimensão emocional, pressupõe uma atitude inconformista em relação aos limites da produção de uma história única. Ela é uma postura de entrelaçamento de saberes e conhecimentos que permite chegar a um horizonte de entendimento em que as relações de poder cedem o lugar às relações de partilhas.

Por fim, para empreendermos uma investida em um trabalho desta natureza, é preciso salientar que a Ciranda Cartografia de Saberes e Conhecimentos surge como uma opção de trabalho que permite ao pesquisador uma maior aproximação com os sujeitos da sua pesquisa, bem como fomentam outras eituras do que foi pesquisado, além de um rompimento com os pressupostos epistemológicos que direcionam, conduzem e norteiam a construção do conhecimento. É com essa percepção que os convido a cirandar com e entre os saberes e conhecimentos

\section{Referências}

AGAMBEN, Giorgio. O amigo e O que é um dispositivo? Chapecó: Argos, 2014.

ANDRADE, Ilza Araújo Leão de. A importância da extensão universitária na estruturação dos novos currículos. In: CABRAL NETO, Antônio (Org.). Flexibilização curricular: cenários e desafios. Natal: EDUFRN, 2004. p. 37-39. 
BORBA, Sérgio da Costa. Aspectos do conceito de multirreferencialidade nas ciências e nos espaços de formação. In. BARBOSA, Joaquim (Org.). Reflexões em torno da abordagem multuirreferencial. São Carlos: Ed. UFSCar, 1998, p. 11-19.

BORBA, Sérgio. Jacques Ardoino: espaços de formação, implicação e multirreferencia. In. MACEDO, Roberto Sidnei; BARBOSA, Joaquim Gonçalves; BORBA, Sérgio. (Org.). Jacques Ardoino e a educação. Belo Horizonte: Autêntica, 2012. p. 81-86.

BRITO, Francisco Jorge de Oliveira; HETKOWSKI, Tânia Maria. LINGUAGEM CARTOGRÁFICA: discussão e contemporaneidade. Anais do IV Encontro Interdisciplinar de Cultura, Tecnologias e Educação - INTERCULTE. 2009. Disponível em: <www.unijorge.edu.br/pdfs/modelo_artigo_interculte.pdf $>$ Acesso em Novembro de 2011.

CUNHA, Teresa. Justiça cognitiva, identidades e diásporas: o cabo dos trabalhos. Revista Electrônica dos Programas de Mestrado e Doutoramento do CES/FEUC/FLUC. No 1 , 2006. Coimbra. Disponível em <www.cabodostrabalhos.ces.uc.pt/ensaios.php > Acessado em maio de 2012.

DUARTE. Paulo Araújo. Cartografia temática. Florianópolis: UFSC, 1991.

FLEURY. Reinaldo Matias. Intercultura e educação. Revista Brasileira de Educação. Maio/Jun/Jul/Ago, n. 23, 2003. pp. $16-35$.

JOLY, Fernando. A cartografia. Trad. Tânia Pellegrini. 6 ed. São Paulo: Papirus, 1990.

MACEDO, Roberto Sidnei. A etnopesquisa crítica e multirreferencial nas Ciências Humanas e na Educação. Salvador: EDUFBA, 2000.

MARTINS, João Batista. Multirreferencialidade e educação. In. BARBOSA, Joaquim (Org.). Reflexões em torno da abordagem multuirreferencial. São Carlos: EdUFSCar, 1998, p. 21 -34 .

MORIN, Edgar. Introdução ao pensamento complexo. Trad. Eliane Lisboa. 3 ed. Porto Alegre: Sulina, 2007.

PIMENTEL, Álamo Gonçalves. Po(éticas) de formação nas traduções interculturais que vêm da periferia. In. PIMENTEL, Álamo Gonçalves; GALEFFI, Dante; MACEDO, Roberto Sidnei. Po(Éticas) da formação: experimentações éticas e estéticas no acontecer formacional. Salvador: EDUFBA, 2012. p. 19 - 60.

RODRIGUES, Silvio Carlos; SOUZA, Luís Humberto de Freitas. Comunicação gráfica: bases conceituais para o entendimento da linguagem cartográfica. GEOUSP - Espaço e Tempo, São Paulo, Nº 23, pp. 65 - 76, 2008.

SANTOS, Boaventura de Sousa. Para um novo senso comum: a ciência, o direito e a política na transição paradigmática. 5 ed. São Paulo: Cortez, 2005.

SANTOS, Boaventura de Sousa. O Fórum Social Mundial: manual de uso. Madison. Disponível em < $\underline{\text { www.ces.uc.pt/documentos/fsm.pdf }>2004 . ~}$ 
SANTOS, Boaventura de Sousa. A globalização e as ciências sociais. 2 ed. São Paulo: Cortez, 2002.

SANTOS, Boaventura de Sousa. Pela mão de Alice: o social na pós-modernidade. 7. ed. São Paulo: Cortez, 2000.

SANTOS, Milton. Por uma outra globalização: do pensamento único à consciência universal. São Pauto: Record, 2000a.

SANTOS JÚNIOR, Alcides Leão. Extensão universitária e os entre-laços dos saberes. 2013. 247f. Tese de Doutorado (Programa de Pós Graduação em Educação). Universidade Federal da Bahia. Faculdade de Educação, Salvador.

Dr. Alcides Leão Santos Júnior

Universidade do Estado do Rio Grande do Norte - Brasil Programa de Pós-Graduação em Planejamento e Dinâmicas Territoriais do Semiárido Membro do Núcleo de Pesquisas Educacionais (NUPED/UERN)

E-mail: santosjunioralcides@gmail.com

Dr. Álamo Gonçalves Pimentel

Universidade Federal do Sul da Bahia - Brasil

Pós-Doutor em Sociologia do Conhecimento (CES/UC)

E-mail: alamopimentelmcz@gmail.com

Recebido em: 26 de setembro de 2016

Aprovado em: 19 de outubro de 2016 